\title{
Effect of acid corrosion on crack propagation of concrete beams
}

\author{
HU SHAOWEI ${ }^{1,2}$, CHEN QIYONG $^{1, *}$ and GONG NINA ${ }^{1}$ \\ ${ }^{1}$ College of Mechanics and Materials, Hohai University, Nanjing 210024, China \\ ${ }^{2}$ Department of Materials and Structure Engineering, Nanjing Hydraulic Research Institute, Nanjing 210029, \\ China \\ e-mail: chenqiyong@outlook.com
}

MS received 30 November 2016; revised 22 May 2017; accepted 16 June 2017; published online 10 March 2018

\begin{abstract}
The effect of acid corrosion on crack propagation of concrete beams was theoretically studied by the method of crack extension resistance curve. Based on this method, a calculation approach was proposed to determine fracture stress intensity factors in crack propagation of concrete beams. Loop iteration analysis was carried out to calculate maximum bearing capacity load, unstable crack toughness, resistance toughness curve, cohesive toughness curve and load-crack mouth opening displacement. Both bilinear and nonlinear softening traction-separation curves were adopted for each of these calculation parameters. The analysis results of each showed the effect of acid corrosion degrees. The influence of acid corrosion on fracture properties was discussed through the calculated results of cohesive toughness curves. These five kinds of simulated results were basically consistent, before the load attained the maximum value. However, with further crack propagation, cohesive toughness of nonlinear softening model was significantly larger than that of bilinear softening model, and the descending branch of $P$-CMOD curve by nonlinear law is higher than that by bilinear law. To validate the approach, tests of specimens under six different corrosion periods were experimentally studied, using three-point bending notched concrete beams soaked in sulphuric acid solution. The Double- $K$ fracture parameters were investigated based on the test results, and load-crack mouth opening displacement curves for different acid conditions were obtained using synchronous sampling of a load sensor and clip-gauge. Numerical results by bilinear softening model showed a good correlation with the experimental ones.
\end{abstract}

Keywords. Concrete beam; acid corrosion; crack propagation; fracture parameters; $K_{\mathrm{R}}$-curve; $P-\mathrm{CMOD}$ curve.

\section{Introduction}

Acid rain pollution has been an alarming issue in environmental engineering as a result of rapid industrialization. In China, almost 2.8 million square metres of land has suffered from acid rain. Adverse effects of acid pollution on forest, vegetation, lakes and soil have been recognized by common research, as well as mechanical properties degradation of concrete structures exposed to these experiments, which was on account of dissolving erosion reaction [1]. Generally, due to weak tensile mechanical property of concrete, as well as heat reactions in the hydration process, concrete structures often incur cracks; as a result of this, structures exposed to acid-polluted environment are likely to have lower bearing capacity. Acidic attack causes the further extension of these cracks. Meanwhile, it is the existence of these induced cracks that facilitates the propagation of the acid attack on the concrete members. Structures subjected to the coupling influence of this

*For correspondence phenomenon experience rapid decrease in their structural capacity and reduction in their service life span.

As a common construction material, concrete is widely used due to its superior properties, such as high compressive strength, low price, convenient construction modelling and workability, as well as corrosion resistance (compared with steel structures). Hence, concrete structures are frequently subjected to acid environment, such as foundation in acid soil or buildings in acid rain pollution areas; the mechanical properties of concrete significantly deteriorate due to exposure to acid corrosion. Therefore, it is essential to identify the influence of acid corrosion on residual fracture properties, to predict crack propagation and failure response of concrete structures [2]. Most studies have been concentrated on the reduced strength or modulus of concrete subjected to acid erosion [3,4]. Only a few studies have focussed on fracture behaviour parameters of concrete, such as fracture energy, fracture toughness, crack propagation and so on, which is useful for assessment of structure safeties [5]. Fracture properties of epoxy polymer concrete exposed to different degradation agents were 
studied with three-point bending notched beams, which were soaked in a solution with $\mathrm{pH}$ value varying from 1.2 to 12.8. These test results showed that the elastic modulus and fracture parameters of concrete structures reduced obviously along with acidity increment in solution [6]. Impact of nitric acid on fracture properties of concrete was investigated using three-point bending beams, and chronical deterioration regularity of fracture properties was derived on the basis of the test mentioned above [7].

Fracture toughness of concrete, which represents crack resistance capacity of concrete, is one of the fundamental fracture parameters in the fracture analysis of concrete [8]. However, due to nonlinear characteristics of concrete materials, the classical linear elastic fracture mechanics cannot be applied to concrete-like materials. Thus, great efforts have been made in the applications of concrete crack extension resistance curve in concrete fracture domain [9], which is used to explain the complete process of fracture [10]. This curve could determine nonlinear regions in crack tip and cohesive fracture toughness of concrete crack propagation. Based on fracture energy and size effect law, the expression of $R$ (resistance curve) was obtained by regression analysis, which was proposed by Bažant [11]. $\mathrm{Xu}$ and Reinhardt [12] put forward $K_{\mathrm{R}}$-curve in terms of stress intensity factor, based on a fictitious crack model [8]. It was stated that crack extension resistance was determined by a combination of the initial fracture toughness and cohesive force along the fictitious crack zone. $K_{\mathrm{R}}$-curve was calculated through experimental $P$-crack mouth opening displacement (CMOD) curve. Kumar and Barai [13] also obtained $K_{\mathrm{R}}$-curve using weight function method. It was proved that the computation efficiency was improved without obvious error when weight function method was applied. Based on crack propagation criterion for mode-I [14], Dong et al [15] proposed a new calculation model for $K_{\mathrm{R}}$-curve with the initial fracture toughness $K_{I \mathrm{c}}^{\text {ini }}$ as initial input parameter. On the basis of this model, $K_{\mathrm{R}}$-curve and $P-$ CMOD curve were obtained by a finite element method. Yu et al [16], on the other hand, determined $K_{\mathrm{R}}$-curve of concrete exposed to high temperature on the basis of a fictitious crack model. Meanwhile, the influences of specimen type, size and fracture process zone (FPZ) length on $K_{\mathrm{R}}$-curve were studied.

In order to study the durability of concrete structure in pollution areas, this paper presents an evaluation method to describe acid corrosion effects on concrete structures, to estimate the residual fracture properties of concrete structures under harsh environmental conditions in practical engineering. It provides a numerical calculation approach to simulate the whole crack propagation in concrete considering the different corrosion degrees, based on the crack extension resistance curve. Moreover, the effects of acid corrosion on the residual fracture behaviour were investigated with two kinds of softening curve laws. The calculated fracture parameters, including maximum load, unstable fracture toughness, $K_{\mathrm{R}}$-curve, cohesive toughness curves and $P-\mathrm{CMOD}$ curve, were analysis results determined by the concrete compressive strength under different corrosion periods, which corresponded to the effect of acid corrosion degrees. To evaluate the calculated results, the deterioration regularity of concrete fracture properties tests was obtained with specimens submerged in sulphuric acid solution for different duration lengths. The relationship between crack toughness and corrosion time was obtained from this experiment, on the basis of the Double- $K$ criterion. Experimental $P-\mathrm{CMOD}$ curves were obtained, and compared to the numerical ones to validate the proposed numerical method. Influence of various corrosion actions on fracture properties is discussed, which has a great significance on the appraising of the service performance and fracture analysis of concrete.

\section{Experiment program}

Six groups with five specimens of each were used as standard three-point bending beams, as shown in figure 1, to examine fracture parameters of concrete with different corrosion periods. The dimensions of specimens are $L \times h \times b=1000 \mathrm{~mm} \times 200 \mathrm{~mm} \times 120 \mathrm{~mm}$, with initial notch length $a_{0}$ being $80 \mathrm{~mm}$ for all, leading to a notchheight ratio of 0.4 . All specimens were prepared with the Portland concrete in the proportion of 1:2.09:2.94:0.51 (cement:sand:coarse aggregate:water). 42.5R ordinary Portland cement, medium river sand and coarse aggregate of green gravel with the maximum size of $28 \mathrm{~mm}$ were used. To obtain specimen mechanical properties, several companion cubes, measuring $150 \mathrm{~mm} \times$ $150 \mathrm{~mm} \times 150 \mathrm{~mm}$, were also prepared from each batch of concrete to evaluate the compressive strength in different corrosion periods. The submerging method suggested by Xie et al [3] was used as the fundamental way in this study. A corrosion-resisting rectangular tank was used as the reservoir for containing acid solution and concrete specimens. Due to the continuous changing of the $\mathrm{pH}$ value of the acid solution along with the chemical neutralization reaction, acid concentration was periodically added to the containment and well monitored using a pH-meter every 3

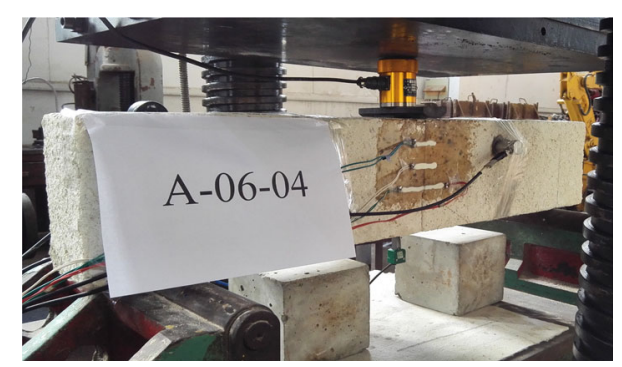

Figure 1. Standard three-point bending beam test. 


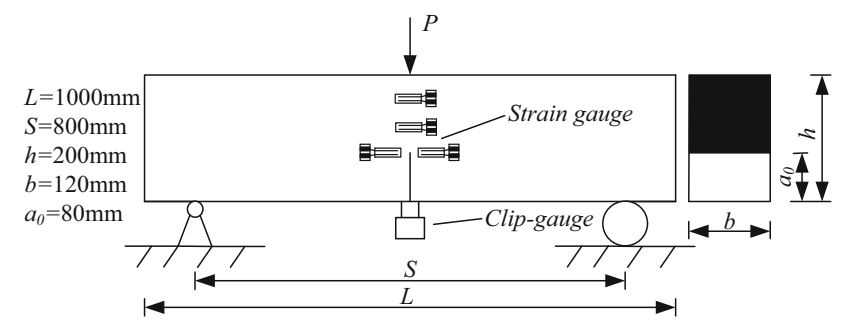

Figure 2. Schematic diagram of experiment test.

$\mathrm{d}$, to maintain a constant $\mathrm{pH}$ value of the acid solution without affecting the chemical reaction in the compartment.

Concrete specimens were cast using wooden formworks. Prefabricated crack was also induced in each specimen before carting green concrete, using a steel plate with thickness of $2 \mathrm{~mm}$ fixed at the middle edges of the formwork, to create a V shape crack. The steel plate was drawn out after initial setting. All samples were preserved in the moulds for the first $48 \mathrm{~h}$, then removed to be cured at room temperature and relative humidity over $90 \%$ for $28 \mathrm{~d}$. Afterwards, specimens were submerged into the reservoir containing sulphuric acid solution with $\mathrm{pH}$ value of 1 for a period of 3-15 months. Tests were conducted using a 500-tonne pressure testing machine shown in figure 1 . With the load sensor in the range of $0-50 \mathrm{kN}$ to measure loads induced by the machine, a clip gauge mechanically attached to the tip of the concrete was used to measure CMOD. There were also four strain gauges attached to concrete at the middle span of each specimen. Two strain gauges were arranged at the trisection point of the plumb line from crack tip to upper edge of the beam. The others were arranged symmetrically around the initial crack tip zone to monitor initial cracking, with the distance of the two strain gauges $10 \mathrm{~mm}$ apart, as shown in figure 2. The companion cubes in different corrosion stages are shown in figure 3 .

\section{Crack propagation criterion}

According to the Double- $K$ fracture criterion, crack propagation can be divided into three distinct phases: crack initiation, stable propagation and unstable propagation. Based on the fictitious crack model, crack propagation is affected by the cohesive force $\sigma(w)$ along fictitious crack zone, so the corresponding stress intensity factor expression can be expressed as follows [17]:

$$
K_{I \mathrm{c}}^{\mathrm{ini}}=K_{I P}-K_{I \sigma}
$$

where $K_{I P}$ is the stress intensity factor at crack tip provided by load $P$ and $K_{I \sigma}$ is the stress intensity factor at crack tip induced by cohesive force $\sigma(w) . K_{I \mathrm{c}}^{\mathrm{ini}}$ represents initial fracture toughness. The crack propagation is considered to be a combination of several different crack initiations [18]. The criterion is as follows:

(1) crack propagation does not occur if $K_{I P}-K_{I \sigma}<K_{I \mathrm{c}}^{\mathrm{ini}}$;

(2) crack propagation occurs at critical state if $K_{I P}$ $K_{I \sigma}=K_{I \mathrm{c}}^{\mathrm{ini}}$;

(3) crack propagates if $K_{I P}-K_{I \sigma}>K_{I \mathrm{c}}^{\mathrm{ini}}$.

On the basis of the $K_{\mathrm{R}}$-curve, the crack extension resistance consists of two parts. The first part is due to the inherent toughness of the material, which is caused by hardened cement material, termed initiation toughness. The second part is due to the extension of main crack, which is caused by the bonding force between aggregate and mixture, termed cohesive toughness. It is equal to the energy that overcomes aggregate adhesion and interlock [19]. Hence, $K_{\mathrm{R}}$-curve can be expressed as follows:

$$
K_{R}(\Delta a)=K_{I c}^{i n i}+K^{c}(\Delta a)
$$

where $K_{I \mathrm{c}}^{\mathrm{ini}}$ is the initiation toughness and $K^{\mathrm{c}}(\Delta a)$ is cohesive fracture toughness.

During the crack propagation process, the propagation criterion can be described with the following formulae:

$$
K_{I P}(\Delta a)=K_{I c}^{i n i}+K^{c}(\Delta a) .
$$

Substituting Eq. (2) in Eq. (3), Eq. (4) can be obtained:

$$
K_{I P}(\Delta a)=K_{R}(\Delta a)=K_{I c}^{i n i}+K^{c}(\Delta a)
$$

where $\Delta a$ is the length of crack extension at load $P$, i.e., $\Delta a=a-a_{0}$. Therefore, from Eq. (4), a function is established between the length of crack extension $\Delta a$ and the stress intensity factor caused by load $P$ corresponding to $\Delta a$; thus, the $K_{\mathrm{R}}$-curve can be determined.

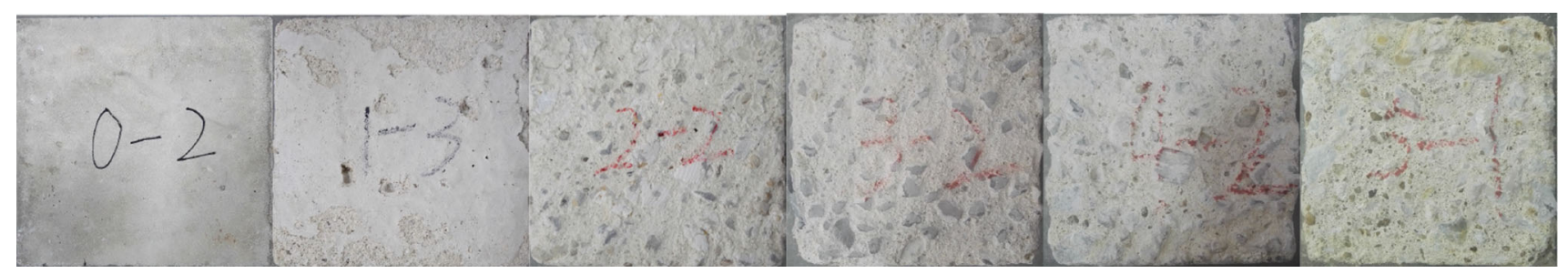

Figure 3. Concrete cube in different corrosion stages. 


\section{Determination of $K_{\mathrm{R}}$-curve}

$K_{I P}(\Delta a), K_{I \sigma}$ and $K_{I \mathrm{c}}^{\mathrm{ini}}$ are necessary in order to determine $K_{\mathrm{R}}$-curve during the entire fracture process. The initial fracture toughness $K_{I \mathrm{c}}^{\mathrm{ini}}$ is the parameter related to material properties. The stress intensity factor caused by load $P$, for three-point bending beams, can be calculated by the following formula [12]:

$$
K(P, a)=\frac{1.5\left(P+\frac{W}{2} \times 10^{-2}\right) \times 10^{-3} S a^{1 / 2}}{t h^{2}} F(\alpha)
$$

where $\alpha=\frac{a}{h}, F(\alpha)=\frac{1.99-\alpha(1-\alpha)\left(2.15-3.93 \alpha+2.7 \alpha^{2}\right)}{(1+2 \alpha)(1-\alpha)^{3 / 2}} ; P$ is the applied external load and $a$ is the effective crack length; $h$, $t$ and $S$ are the depth, width and loading span of the beam, respectively.

According to the fictitious crack model, stable propagation of main crack exists before unstable propagation. The cohesive force $\sigma_{w}(x)$ is considered to act on both sides of the fictitious crack zone, and it is calculated by the softening traction-separation law [20]. The stress intensity factor caused by cohesive force can be determined by the following equation [21]:

$$
K^{c}(\Delta a)=\int_{a_{0}}^{a} 2 \sigma(x) F\left(\frac{x}{a}, \frac{a}{h}\right) / \sqrt{\pi a} d x
$$

where

$$
\begin{aligned}
F\left(\frac{x}{a}, \frac{a}{h}\right)=\frac{3.52\left(1-\frac{x}{a}\right)}{\left(1-\frac{a}{h}\right)^{3 / 2}}-\frac{4.35-5.28 \frac{x}{a}}{\left(1-\frac{a}{h}\right)^{1 / 2}} \\
+\left\{\frac{1.30-0.3\left(\frac{x}{a}\right)^{3 / 2}}{\left[1-\left(\frac{x}{a}\right)^{2}\right]^{1 / 2}}+0.83-1.76 \frac{x}{a}\right\} \\
\cdot\left\{1-\left(1-\frac{x}{a}\right) \frac{a}{h}\right\}
\end{aligned}
$$

The function of cohesive force along the FPZ is considered to be nonlinear for quasi-brittle materials like concrete [22]. On the basis of axial tensile experiments, several softening traction-separation laws with different forms have been proposed, including a bilinear curve and a nonlinear curve [23]. These two kinds of curves mentioned here are adopted to determine the $K_{\mathrm{R}}$-curve in this paper [24].

A: Bilinear softening traction-separation law

The bilinear softening traction-separation law can be expressed with Eq. (8), and the curve as shown in figure 4:

$$
\sigma(x)= \begin{cases}f_{t}-\left(f_{t}-\sigma_{s}\right)\left(w / w_{s}\right), & 0 \leq w \leq w_{s} \\ \sigma_{s}\left(w_{0}-w\right) /\left(w_{0}-w_{s}\right), & w_{s} \leq w \leq w_{0} \\ 0, & w \geq w_{0}\end{cases}
$$

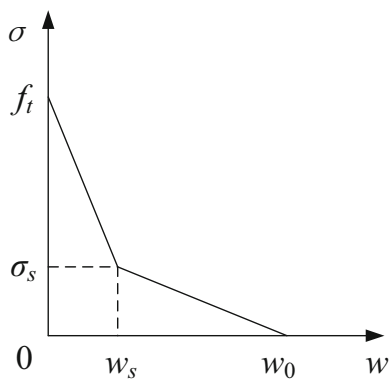

Figure 4. Bilinear softening traction-separation law.

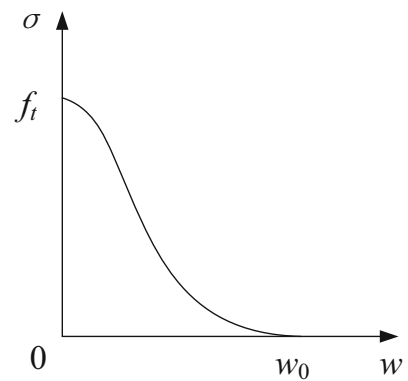

Figure 5. Nonlinear softening traction-separation law.

where $f_{\mathrm{t}}$ is the tensile strength; $\sigma_{\mathrm{s}}$ and $w_{\mathrm{s}}$ are, respectively, the stress and displacement corresponding to the turning point of the curve; $w_{0}$ is the critical crack opening width when the cohesive force is equal to zero.

B: Nonlinear softening traction-separation law

The nonlinear softening traction-separation law proposed by $\mathrm{Xu}$ and Reinhardt [12] is shown in figure 5, and represented by Eq. (9):

$$
\begin{aligned}
\frac{\sigma}{f_{t}}= & {\left[1+\left(c_{1} \frac{w}{w_{0}}\right)^{3}\right] \cdot \exp \left(-c_{2} \frac{w}{w_{0}}\right) } \\
& -\frac{w}{w_{0}}\left(1+c_{1}^{3}\right) \exp \left(-c_{2}\right)
\end{aligned}
$$

where $c_{1}, c_{2}$ are the material parameters.

The crack opening displacement $w(x)$ along FPZ can be expressed with Eq. (10), proposed by Jenq and Shah in 1985 [14]:

$$
\begin{aligned}
& w=C M O D \\
& \left\{(1-x / a)^{2}+[1.081-1.149(a / h)]\left[x / a-(x / a)^{2}\right]\right\}^{1 / 2}
\end{aligned}
$$

In this case, CMOD of a three-point bending beam is calculated by Eq. (11), which was suggested by Tada in 2002 [21]: 


$$
\begin{aligned}
& C M O D= \\
& \frac{24 P \lambda}{E B}\left[0.76-2.28 \lambda+3.87 \lambda^{2}-2.04 \lambda^{3}+\frac{0.66}{(1-\lambda)^{2}}\right]
\end{aligned}
$$

where $E$ is elastic modulus, $\lambda=\left(a+H_{0}\right) /\left(D+H_{0}\right)$, and $H_{0}$ is thickness of the blade.

The loading stages during an entire fracture process can be characterized by four different situations of crack propagation: (1) $a=a_{0}$; (2) $a_{0} \leq a \leq a_{\mathrm{s}}$; (3) $a_{\mathrm{s}} \leq a \leq a_{w}$ and (4) $a \geq a_{w_{0}}$ where $a_{0}$ is the initial length of prefabricated crack and $a_{\mathrm{s}}$ is the critical crack length when $w$ is equal to $w_{\mathrm{s}}$. In the critical situation, the load reaches its maximum value, and crack tip opening displacement (CTOD) achieves its critical value CTOD $_{c} ; a_{w}$ is the characteristic crack length when CTOD arrives at the maximum value $w_{0}$ on the softening traction-separation curve. According to these four stages, the expression of crack extension resistance curves using different distribution functions of the cohesive force along the fictitious crack zone can be shown as follows [14]:

(1) $a=a_{0}$

The crack extension resistance has a constant value of $K_{I \mathrm{c}}^{\mathrm{ini}}$, expressed as Eq. (12):
In this interval, crack is in the stable propagation stage, and the distribution of the cohesive force along the fictitious crack zone is illustrated with figure 6, expressed by Eq. (13):

$$
\sigma(x)=\sigma(w)+\left[f_{t}-\sigma(w)\right]\left(x-a_{0}\right) /\left(a-a_{0}\right)
$$

where $w$ is the opening width at the tip of prefabricated crack; $\sigma_{w}$ is cohesive force at the point of the tip of prefabricated crack, which is calculated by a bilinear softening traction-separation law or nonlinear one; $f_{\mathrm{t}}$ is the tensile strength of the material tested. The crack extension resistance curve, $K_{\mathrm{R}}$-curve, can be achieved based on the cohesive force along the fictitious crack zone as follows:

$$
K_{R}(\Delta a)=K_{I c}^{i n i}+\int_{a_{0}}^{a} 2 \sigma(x) F\left(\frac{x}{a}, \frac{a}{h}\right) / \sqrt{\pi a} \mathrm{~d} x
$$

(3) $a_{\mathrm{s}} \leq a \leq a_{w}$

When the loading exceeds the maximum value $P_{\max }$, the crack propagation is unstable. The crack length and the CTOD have passed their critical values $a_{\mathrm{c}}$ and $\mathrm{CTOD}_{\mathrm{c}}$, respectively. The distribution shape of the cohesive force on the fictitious crack zone should be bilinear, expressed as Eq. (15):

$$
\sigma(x)= \begin{cases}\sigma_{1}(x)=\sigma(w)+\left[\sigma_{s}-\sigma(w)\right]\left(x-a_{0}\right) /\left(a-a_{s}\right) & a_{0} \leq x \leq a-a_{s}+a_{0} \\ \sigma_{2}(x)=\sigma_{s}+\left[f_{t}-\sigma_{s}\right]\left(x-a+a_{s}-a_{0}\right) /\left(a_{s}-a_{0}\right) & a-a_{s}+a_{0} \leq x \leq a\end{cases}
$$

$$
K_{R}(\Delta a)=K_{I \mathrm{c}}^{\mathrm{ini}}
$$

(2) $a_{0} \leq a \leq a_{\mathrm{s}}$

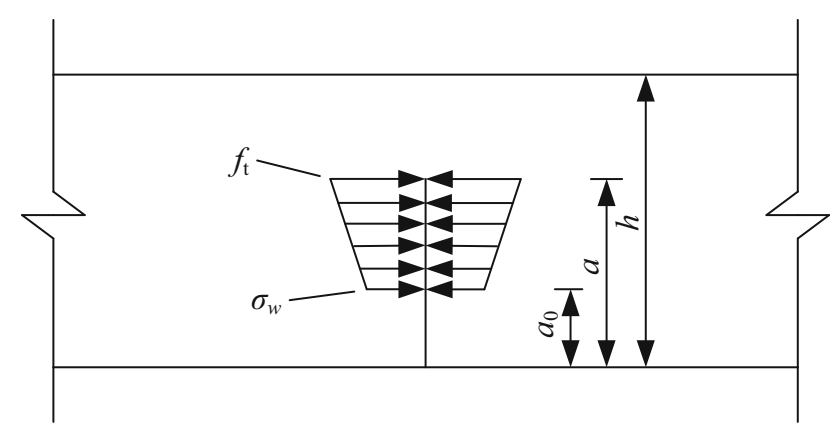

Figure 6. Cohesive force distribution along the fictitious crack zone for $a_{0} \leq a \leq a_{\mathrm{s}}$.
The crack extension resistance can be calculated by the following equation:

$$
\begin{aligned}
K_{R}(\Delta a)= & K_{I c}^{i n i}+\int_{a_{0}}^{a} 2 \sigma(x) F\left(\frac{x}{a}, \frac{a}{h}\right) / \sqrt{\pi a} \mathrm{~d} x \\
= & K_{I c}^{i n i}+\int_{a_{0}}^{a-a_{s}} 2 \sigma_{1}(x) F\left(\frac{x}{a}, \frac{a}{h}\right) / \sqrt{\pi a} \mathrm{~d} x \\
& +\int_{a_{s}}^{a} 2 \sigma_{2}(x) F\left(\frac{x}{a}, \frac{a}{h}\right) / \sqrt{\pi a} \mathrm{~d} x
\end{aligned}
$$

(4) $a \geq a_{w}$

In this stage, the $P-C M O D$ curve is in the descending stage. The crack length exceeds its critical value $a_{w}$, and a complete distribution of cohesive force is shown on the fictitious crack zone. A new stress-free crack appears in front of the preformed crack. The cohesive force can be determined with the following equations: 


$$
\sigma(x)= \begin{cases}\sigma_{1}(x)=0 & a_{0} \leq x \leq a-a_{w}+a_{0} \\ \sigma_{2}(x)=\sigma_{s}\left(x-a+a_{w}-a_{0}\right) /\left(a_{w}-a_{s}\right) & a-a_{w}+a_{0} \leq x \leq a-a_{s}+a_{0} \\ \sigma_{2}(x)=\sigma_{s}+\left[f_{t}-\sigma_{s}\right]\left(x-a+a_{s}-a_{0}\right) /\left(a_{s}-a_{0}\right) & a-a_{s}+a_{0} \leq x \leq a\end{cases}
$$

Thus

$$
\begin{aligned}
K_{R}(\Delta a)= & K_{I c}^{i n i}+\int_{a_{0}}^{a} 2 \sigma(x) F\left(\frac{x}{a}, \frac{a}{h}\right) / \sqrt{\pi a} \mathrm{~d} x \\
= & K_{I c}^{i n i}+\int_{a_{0}-a_{w}}^{a-a_{s}} 2 \sigma_{2}(x) F\left(\frac{x}{a}, \frac{a}{h}\right) / \sqrt{\pi a} \mathrm{~d} x \\
& +\int_{a_{s}}^{a} 2 \sigma_{3}(x) F\left(\frac{x}{a}, \frac{a}{h}\right) / \sqrt{\pi a} \mathrm{~d} x
\end{aligned}
$$

For the complete loading process, distribution shape of cohesive force is determined first; then the $K_{\mathrm{R}}$-curve can be obtained based on cohesive fracture toughness. The calculation procedure is as follows:

1. Input the required material parameters, including the specimen size, initial crack length $a_{0}$, the initial crack toughness (load), calculated concrete elastic model and the fracture energy and axial tensile strength, denoted as $P=P_{\text {ini }}$, which is obtained from the experiment.

2. Specify the expansion of the effective crack length increment, $a=a+\Delta a, \Delta a=0.0001 \mathrm{~m}$; apply the increment of external load, $P=P+\Delta P, \Delta P=0.0001 \mathrm{kN}$

3. Calculate $K_{I P}(\Delta a)$ and $K^{\mathrm{c}}(\Delta a)$ by adjusting load $P$ until Eq. (4) is satisfied. When $K_{I P}(\Delta a)<K_{I \mathrm{c}}^{\mathrm{ini}}+K^{\mathrm{c}}(\Delta a)$, load is increased with a load increment $\Delta P$ and cohesive stress $K^{\mathrm{c}}(\Delta a)$ is recalculated based on the displacement due to the new load $P$. When $K_{I P}(\Delta a)=K_{I \mathrm{c}}^{\text {ini }}+K^{\mathrm{c}}(\Delta a)$, load is decreased with a load decrement $\Delta P$; once $K_{I P}(\Delta a)>K_{I \mathrm{c}}^{\mathrm{ini}}+K^{\mathrm{c}}(\Delta a)$, the increase of the applied load is terminated and the maximum load is determined, using two standards.

4. Apply another iterative numerical process using the parameters of effective crack length $a$ and external load force $P$ obtained from the previous steps; specify the expansion of the effective crack length increment, $a=a+\Delta a, \Delta a=0.0001 \mathrm{~m}$; apply the decrement of external load, $P=P-\Delta P, \Delta P=0.0001 \mathrm{kN}$.

5. Calculate $K_{I P}(\Delta a)$ and $K^{\mathrm{c}}(\Delta a)$ by adjusting load $P$ until Eq. (4) is satisfied. The iterative process is terminated when the crack tip is close to the boundary of beam.

It can be seen from figure 7 that the applied load $P$ and the corresponding crack propagation length $a$ can be obtained in the iteration process, as well as the fracture parameters, such as $K_{I P}(\Delta a), K^{\mathrm{c}}(\Delta a)$ and CMOD. During the calculation process, the maximum load is determined through two standards; hence, more accurate critical effective crack length and $P-$ CMOD curves are derived.

\section{Calculation results}

\subsection{Material parameters}

Four parameters are necessary for the calculation: initial crack load $P_{\text {ini }}$, elastic modulus $E_{\mathrm{c}}$, the tensile strength $f_{\mathrm{t}}$ and fracture energy $G_{\mathrm{F}} . P_{\text {ini }}$ was obtained according to the variation of the strain gauge at the tip of precast notch. $G_{\mathrm{F}}, f_{\mathrm{t}}$ and $E_{\mathrm{c}}$ can be determined through following the equations, which were suggested in CEB-FIB Model Code 2010 [25]:

$$
\left\{\begin{array}{l}
G_{F}=\left(0.0204+0.0053 d_{\max }^{0.95} / 8\right)\left(f_{c m} / f_{c m 0}\right)^{0.7} \\
f_{t}=0.4983 \sqrt{f_{c m}} \\
E_{c}=E_{c 0} \alpha\left(f_{c m} / f_{c m 0}\right)^{1 / 3}
\end{array}\right.
$$

where $f_{\mathrm{ck} 0}=f_{\mathrm{cm} 0}=10 \mathrm{MPa}, f_{\mathrm{cm}}=f_{\mathrm{ck}}+\Delta f, \Delta f=8 \mathrm{MPa}$, $E_{\mathrm{c} 0}=21.5 \times 10^{9} \mathrm{~Pa}, \alpha=1.0$ and $d_{\text {max }}=28 \mathrm{~mm} ; f_{\mathrm{ck}}$ is the concrete cylinder compressive strength, determined by conversion of the cube compressive strength. Parameters of bilinear softening traction-separation law are obtained through the following equation proposed by $\mathrm{Xu}$ [17]:

$$
\left\{\begin{array}{l}
\sigma_{s}=\left(2-0.4 \sqrt{\alpha_{F}}\right) f_{t} / \alpha_{F} \\
w_{s}=0.4 \sqrt{\alpha_{F}} G_{F} / f_{t} \\
w_{0}=\alpha_{F} G_{F} / f_{t} \\
\lambda=10-\left(f_{c k} / 2 f_{c k 0}\right)^{0.7} \\
\alpha_{F}=\lambda-d_{\text {max }}^{0.9} / 8
\end{array} .\right.
$$

Parameters of nonlinear softening traction-separation law are obtained by Eqs. (21) [17]:

$$
\left\{\begin{array}{l}
c_{1}=\left(d_{\max } / 8\right)^{0.75} \\
c_{2}=\lambda\left(0.92-d_{\max } / 400\right) \\
w_{0}=\alpha_{F} G_{F} / f_{t m}
\end{array}\right.
$$

The calculated parameters are shown in table 1 .

\subsection{Tests results}

Parameters for three-point bending beams were as follows: $a_{0}=0.08 \mathrm{~m}, \quad h=0.20 \mathrm{~m}, \quad L=4 h, \quad b=0.12 \mathrm{~m}$, $H_{0}=2 \mathrm{~mm}$ and $W=480 \mathrm{~kg} \mathrm{~m} / \mathrm{s}^{2}$. The test results are listed in table 2: 


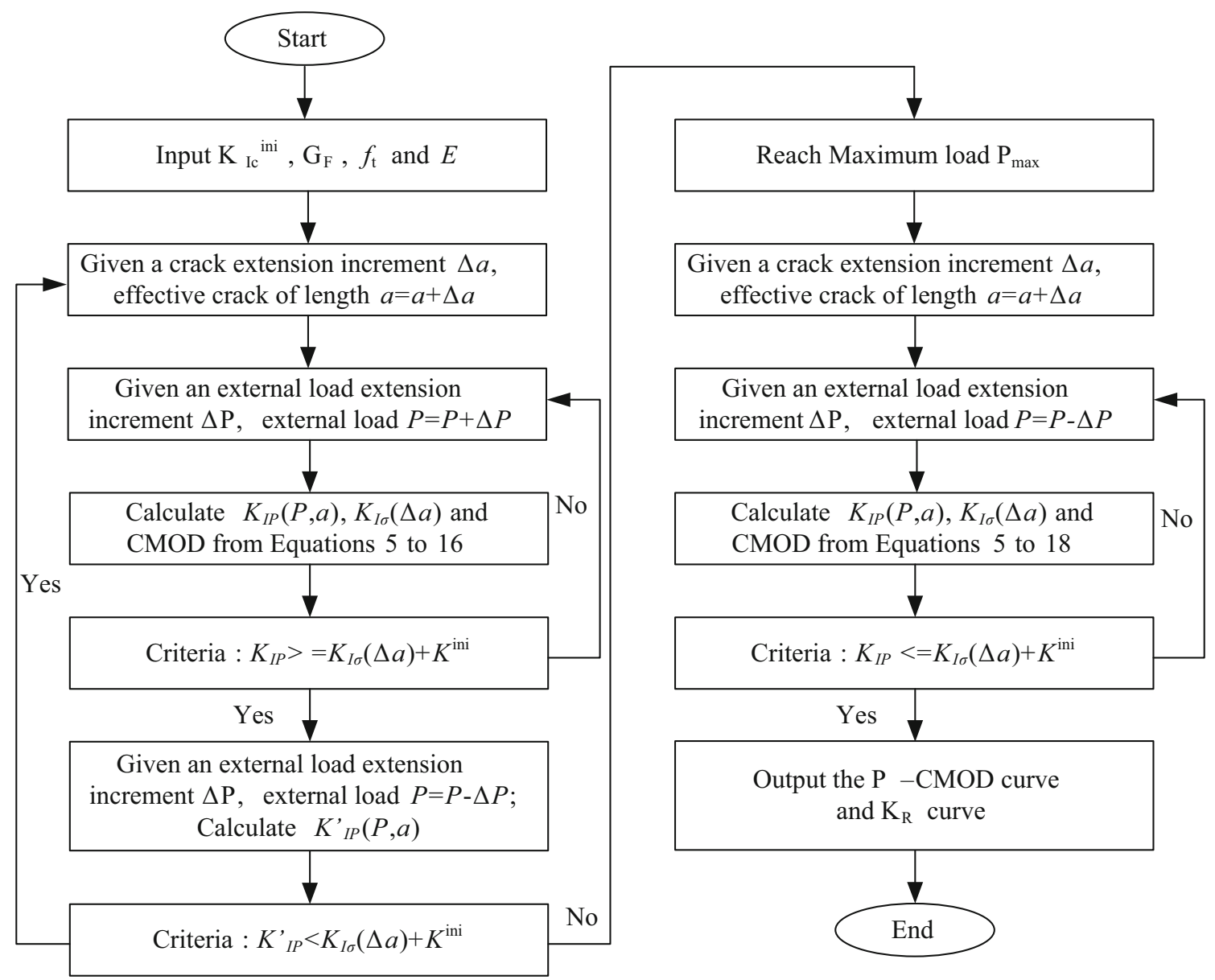

Figure 7. Calculation process diagram.

Table 1. Material parameters.

\begin{tabular}{|c|c|c|c|c|c|c|c|c|}
\hline Time (months) & $f_{\mathrm{ck}}(\mathrm{MPa})$ & $f_{\mathrm{t}}(\mathrm{MPa})$ & $E_{\mathrm{c}}(\mathrm{GPa})$ & $\sigma_{\mathrm{s}}(\mathrm{MPa})$ & $w_{\mathrm{s}}(\mu \mathrm{m})$ & $c_{1}$ & $c_{2}$ & $w_{0}(\mu \mathrm{m})$ \\
\hline 0 & 32.047 & 3.1534 & 34.14 & 0.5231 & 29.9 & 2.5589 & 7.3176 & 184.5 \\
\hline 3 & 25.896 & 2.9011 & 32.29 & 0.4594 & 29.3 & 2.5589 & 7.4815 & 184.1 \\
\hline 6 & 19.548 & 2.6154 & 30.14 & 0.3937 & 28.6 & 2.5589 & 7.6635 & 182.6 \\
\hline 9 & 17.968 & 2.5393 & 29.55 & 0.3772 & 28.4 & 2.5589 & 7.7114 & 182.0 \\
\hline 12 & 14.216 & 2.3487 & 28.05 & 0.3378 & 27.8 & 2.5589 & 7.8307 & 180.2 \\
\hline 15 & 9.296 & 2.0724 & 25.81 & 0.2847 & 26.9 & 2.5589 & 8.0028 & 176.6 \\
\hline
\end{tabular}

From table 2, the average values obviously followed the law despite some discreteness in the tested loads. The initial crack load $P_{\text {ini }}$ and maximum load $P_{\max }$ declined sharply with the increase of corrosion duration. The chemical reaction had a large influence on concrete beams, which were subjected to sulphuric acid. The initial crack load $P_{\text {ini }}$ decreased $2.75 \%$ in 3 -month corrosion. With further increase of corrosion duration, the acid-base neutralization reactant dissolved in the corrosion solution, which led to mortar on surfaces of specimens peeling off. At corrosion period of 6 months, the initial crack load $P_{\text {ini }}$ decreased rapidly. However, unlike $P_{\text {ini }}$, the maximum load $P_{\max }$ dropped continuously with the increase of corrosion duration. At the $15^{\text {th }}$ month, the initial cracking load $P_{\text {ini }}$ and maximum load $P_{\max }$ decreased by $35.62 \%$ and $36.76 \%$, respectively. The ratio of the initial cracking load to the unstable fracture load approximately varied between 0.77 and 0.85 . The decreasing trend of crack load with increasing corrosion period is showed in figure 8 .

Stress intensity factor is a physical quantity that reflects the elasticity intensity of the crack tip stress field. Decrease 
Table 2. Test results.

\begin{tabular}{|c|c|c|c|c|c|c|c|c|}
\hline Number & $\begin{array}{c}P_{\text {ini }} \\
(\mathrm{kN})\end{array}$ & $\begin{array}{l}P_{\max } \\
(\mathrm{kN})\end{array}$ & $\frac{P_{i n i}}{P_{\max }}$ & $\begin{array}{c}a_{\mathrm{c}} \\
(\mathrm{mm})\end{array}$ & $\frac{a_{c}}{h}$ & $\begin{array}{c}K_{I \mathrm{c}}^{\mathrm{ini}} \\
\left(\mathrm{MPa} \cdot \mathrm{m}^{1 / 2}\right)\end{array}$ & $\begin{array}{c}K_{I \mathrm{c}}^{\mathrm{un}} \\
\left(\mathrm{MPa} \cdot \mathrm{m}^{1 / 2}\right)\end{array}$ & $K_{I \mathrm{c}}^{\mathrm{ini}} / K_{I \mathrm{c}}^{\mathrm{un}}$ \\
\hline ТРВ-01 & 5.0332 & 7.8688 & 0.64 & 92.6 & 0.54 & 0.7789 & 1.4364 & 0.54 \\
\hline TPB-02 & 7.4764 & 8.2536 & 0.91 & 90.2 & 0.54 & 1.1398 & 1.4508 & 0.79 \\
\hline TPB-03 & 7.0433 & 8.1133 & 0.87 & 92.8 & 0.54 & 1.0759 & 1.4833 & 0.73 \\
\hline ТРВ-04 & 6.6015 & 8.3951 & 0.79 & 89.3 & 0.51 & 1.0106 & 1.4566 & 0.69 \\
\hline Average & 6.5386 & 8.2540 & 0.79 & 90.8 & 0.54 & 1.0013 & 1.4635 & 0.68 \\
\hline A-03-01 & 6.8371 & 7.7171 & 0.89 & 91.3 & 0.53 & 1.0454 & 1.3814 & 0.76 \\
\hline A-03-02 & 5.7616 & 6.8706 & 0.84 & 94.2 & 0.54 & 0.8865 & 1.2887 & 0.69 \\
\hline A-03-03 & 6.9582 & 7.5882 & 0.92 & 93.6 & 0.52 & 1.0633 & 1.4070 & 0.76 \\
\hline A-03-04 & 5.8779 & 7.8610 & 0.75 & 88.8 & 0.53 & 0.9037 & 1.3549 & 0.67 \\
\hline Average & 6.3587 & 7.4412 & 0.85 & 91.9 & 0.53 & 0.9747 & 1.3580 & 0.72 \\
\hline A-06-01 & 5.4942 & 6.8491 & 0.80 & 94.2 & 0.54 & 0.8470 & 1.2854 & 0.66 \\
\hline A-06-02 & 5.5698 & 6.8664 & 0.81 & 95.0 & 0.54 & 0.8582 & 1.3037 & 0.66 \\
\hline A-06-03 & 5.2706 & 7.7908 & 0.68 & 89.2 & 0.51 & 0.814 & 1.3510 & 0.60 \\
\hline A-06-04 & 6.6992 & 7.3185 & 0.92 & 89.8 & 0.53 & 1.0250 & 1.2832 & 0.80 \\
\hline Average & 5.7584 & 7.2062 & 0.80 & 92.0 & 0.53 & 0.8861 & 1.3058 & 0.68 \\
\hline A-09-01 & 5.5116 & 6.4708 & 0.85 & 93.5 & 0.52 & 0.8496 & 1.2048 & 0.71 \\
\hline A-09-02 & 4.2635 & 6.5661 & 0.65 & 93.2 & 0.54 & 0.6652 & 1.2162 & 0.55 \\
\hline A-09-03 & 5.4858 & 6.7891 & 0.81 & 91.8 & 0.53 & 0.8458 & 1.2293 & 0.69 \\
\hline A-09-04 & 5.5152 & 6.9905 & 0.79 & 92.0 & 0.55 & 0.8501 & 1.2693 & 0.67 \\
\hline Average & 5.1940 & 6.7041 & 0.77 & 92.6 & 0.53 & 0.8027 & 1.2299 & 0.65 \\
\hline A-12-01 & 4.9658 & 5.8947 & 0.84 & 94.7 & 0.53 & 0.7690 & 1.1204 & 0.69 \\
\hline A-12-02 & 3.9746 & 5.4217 & 0.73 & 95.6 & 0.51 & 0.6226 & 1.0495 & 0.59 \\
\hline A-12-03 & 4.9847 & 5.487 & 0.91 & 94.7 & 0.56 & 0.7718 & 1.0461 & 0.74 \\
\hline A-12-04 & 5.2173 & 5.7832 & 0.90 & 96.4 & 0.54 & 0.8061 & 1.1303 & 0.71 \\
\hline Average & 4.7856 & 5.6467 & 0.85 & 95.3 & 0.54 & 0.7424 & 1.0866 & 0.68 \\
\hline A-15-01 & 5.0962 & 5.6795 & 0.90 & 92.5 & 0.53 & 0.7882 & 1.0466 & 0.75 \\
\hline A-15-02 & 3.7432 & 5.782 & 0.65 & 91.1 & 0.54 & 0.5884 & 1.0433 & 0.56 \\
\hline A-15-03 & 4.2455 & 5.0206 & 0.85 & 98.6 & 0.55 & 0.6626 & 1.0209 & 0.65 \\
\hline A-15-04 & 3.7545 & 4.3984 & 0.85 & 100.6 & 0.55 & 0.5901 & 0.9290 & 0.64 \\
\hline Average & 4.2098 & 5.2201 & 0.81 & 95.7 & 0.54 & 0.6573 & 1.0100 & 0.65 \\
\hline
\end{tabular}

Note: in this experiment, TPB is the abbreviation for standard three-point bending notched concrete beam; number 01 represents the first sample of the series of specimens. A-03 represents three-point bending notched concrete beams subjected to acid corrosion for 3 months.

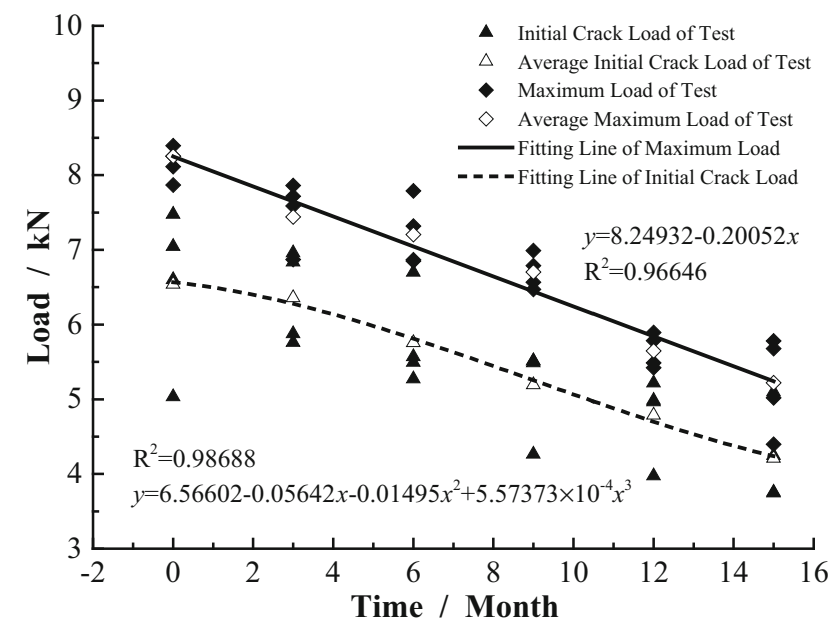

Figure 8. Variation of crack load with acid attack duration. of stress intensity factor describes the recession of bearing capacity of the structure at crack tip field. The deterioration regularity of concrete fracture toughness is in complete accord with that of concrete crack load exposed to acid corrosion. The initial fracture toughness $K_{I \mathrm{c}}^{\text {ini }}$ had a slight variation in the early 3 months and a significant drop in the later period. Compared with the initial fracture toughness, the unstable fracture toughness $K_{I \mathrm{c}}^{\mathrm{un}}$ was more sensitive to acid attack, which is similar to a linear downward trend change law with the increase of corrosion time. Compared with experimental results of TPB specimens, the average initial crack toughness $K_{I \mathrm{c}}^{\text {ini }}$ and unstable crack toughness $K_{I \mathrm{c}}^{\mathrm{un}}$ decreased by $34.36 \%$ and $30.99 \%$, respectively, at $15^{\text {th }}$ month. The ratio of initial fracture toughness to unstable fracture toughness varied between approximately 0.65 and 0.72 . The relationship between crack toughness and corrosion period derived from the experiment is shown in figure 9. 


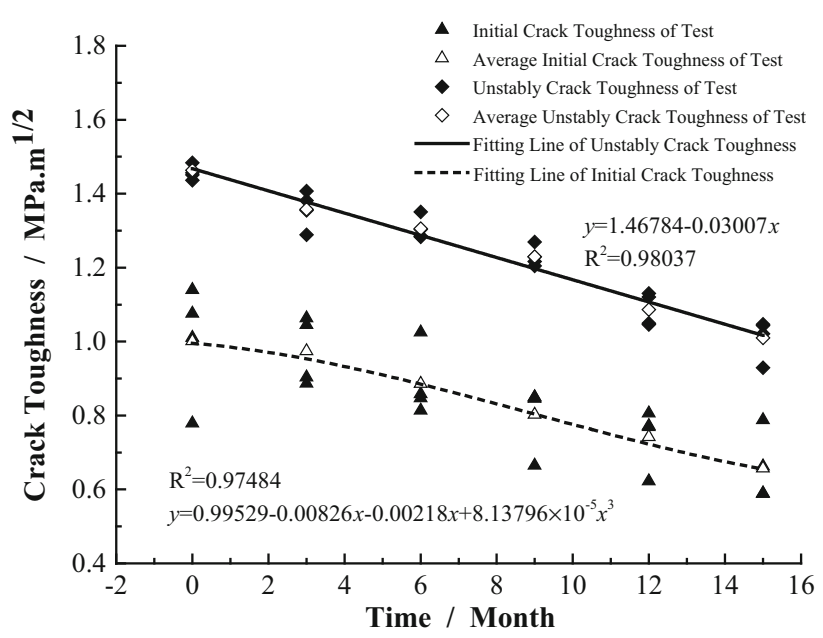

Figure 9. Variation of crack toughness with acid attack duration.

\subsection{Calculation results}

The fracture parameters of concrete beams subjected to acid corrosion were calculated using the average value of initial crack load $P_{\text {ini }}$ by test, based on the method proposed in the paper. The test and calculated results are shown in table 3 .

The data in table 3 are based on the calculation process proposed in this paper. The biggest error between average experimental maximum loads and calculated maximum loads is $10.06 \%$. Meanwhile, the calculated unstable crack toughness is consistent with experimental values, and the largest error between them is $5.08 \%$. The crack load and the unstable fracture toughness by the bilinear softening law are slightly smaller than those by the nonlinear law, and are closer to the experimental results.

Load-crack mouth opening displacement $(P-\mathrm{CMOD})$ curve reflects a number of mechanical properties, such as the maximum load, critical crack mouth opening displacement $\left(\mathrm{CMOD}_{\mathrm{c}}\right)$ and hardening properties. Figures 10 and 11 show the typical entire $P-C M O D$ curves in different corrosion periods by two kinds of softening laws. $P$ CMOD curve of standard three-point bending beam obtained from specimens under ordinary condition is plotted as a reference. The figures show that the maximum load decreased significantly with increasing corrosion durations. Meanwhile, the crack-mouth opening displacement $\left(\mathrm{CMOD}_{\mathrm{c}}\right)$ decreased slightly. The initial slope of ascending stages decreased with the increase of corrosion period, and the curve became more extended. Based on the containing area of the curves and the coordinate axis $X$, the fracture energy could be described by the size of area. Thus, with increasing corrosion duration, the fracture energy decreased, causing the structure to fail easily.

The resistance curve is the stress intensity factors generated by crack resistance forces, namely $K_{\mathrm{R}}$-curve, which is used to describe the fracture properties of the entire propagation. The calculated $K_{\mathrm{R}}$-curves are shown in figures 12 and 13.

The effect of acid corrosion on concrete is reflected in the concrete compressive strength under different corrosion periods. The influence of acid corrosion on fracture properties is seen in the calculated results of cohesive toughness curves, namely $K_{I \sigma}$-curves, which are the stress intensity

Table 3. Comparison of test and calculation results.

\begin{tabular}{|c|c|c|c|c|c|c|}
\hline Number & & $\begin{array}{c}P_{\text {ini }} \\
(\mathrm{kN})\end{array}$ & $\begin{array}{l}P_{\max } \\
(\mathrm{kN})\end{array}$ & $\begin{array}{l}\text { Error } \\
(\%)\end{array}$ & $\begin{array}{c}K_{I \mathrm{c}}^{\mathrm{un}} \\
\left(\mathrm{MPa} \mathrm{m}^{1 / 2}\right)\end{array}$ & Error $(\%)$ \\
\hline \multirow[t]{3}{*}{ Standard } & Average & 6.5386 & 8.2540 & & 1.4635 & \\
\hline & $\mathrm{BFC}$ & & 8.4465 & 2.33 & 1.4841 & 1.41 \\
\hline & NFC & & 8.4498 & 2.37 & 1.5135 & 3.42 \\
\hline \multirow[t]{3}{*}{3 months corrosion } & Average & 6.3587 & 7.4412 & & 1.3580 & \\
\hline & BFC & & 8.0451 & 8.12 & 1.4010 & 3.17 \\
\hline & NFC & & 8.0507 & 8.19 & 1.4270 & 5.08 \\
\hline \multirow[t]{3}{*}{6 months corrosion } & Average & 5.7584 & 7.2062 & & 1.3058 & \\
\hline & $\mathrm{BFC}$ & & 7.2685 & 0.86 & 1.2678 & 2.91 \\
\hline & NFC & & 7.2754 & 0.96 & 1.2916 & 1.09 \\
\hline \multirow[t]{3}{*}{9 months corrosion } & Average & 5.1940 & 6.7041 & & 1.2299 & \\
\hline & $\mathrm{BFC}$ & & 6.7290 & 0.37 & 1.1907 & 3.19 \\
\hline & NFC & & 6.7392 & 0.52 & 1.2174 & 1.02 \\
\hline \multirow[t]{3}{*}{12 months corrosion } & Average & 4.7856 & 5.6467 & & 1.0866 & \\
\hline & $\mathrm{BFC}$ & & 6.2033 & 9.86 & 1.0992 & 1.16 \\
\hline & NFC & & 6.215 & 10.06 & 1.1243 & 3.47 \\
\hline \multirow[t]{3}{*}{15 months corrosion } & Average & 4.2098 & 5.2201 & & 1.0100 & \\
\hline & $\mathrm{BFC}$ & & 5.4555 & 4.51 & 0.9717 & 3.79 \\
\hline & NFC & & 5.4678 & 4.75 & 0.9941 & 1.57 \\
\hline
\end{tabular}

Note: in this calculation, average is the results acquired by the experiments; BFC is the abbreviation for the calculation results by means of bilinear softening traction-separation law; NFC is the abbreviation for the calculation results by means of nonlinear softening traction-separation law. 


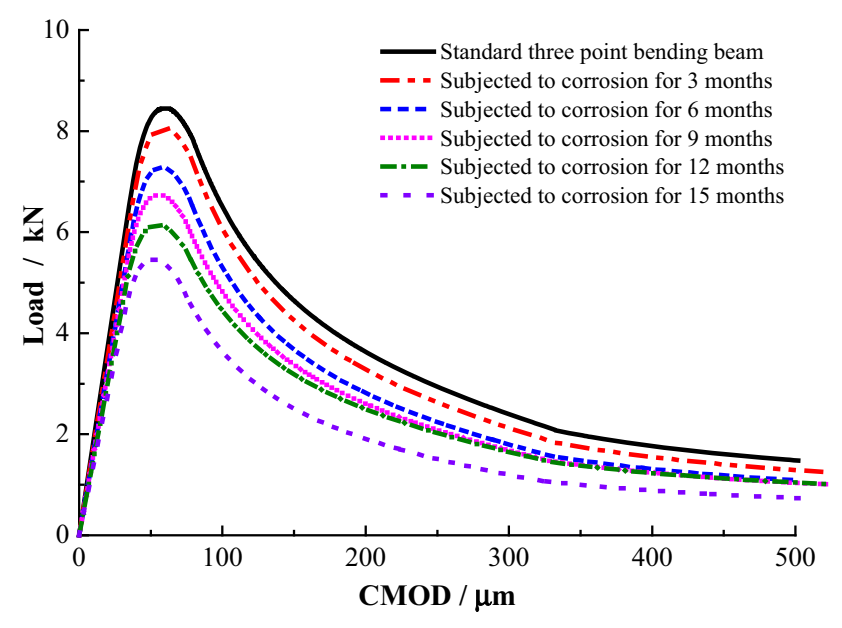

Figure 10. $P-\mathrm{CMOD}$ curves by calculation (bilinear softening curve).

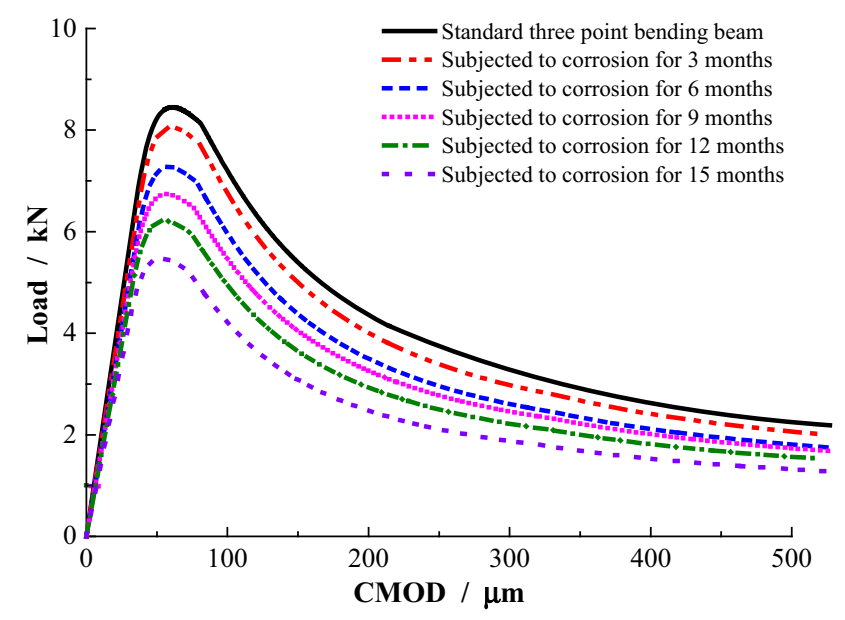

Figure 11. $P-\mathrm{CMOD}$ curves by calculation (nonlinear softening curve).

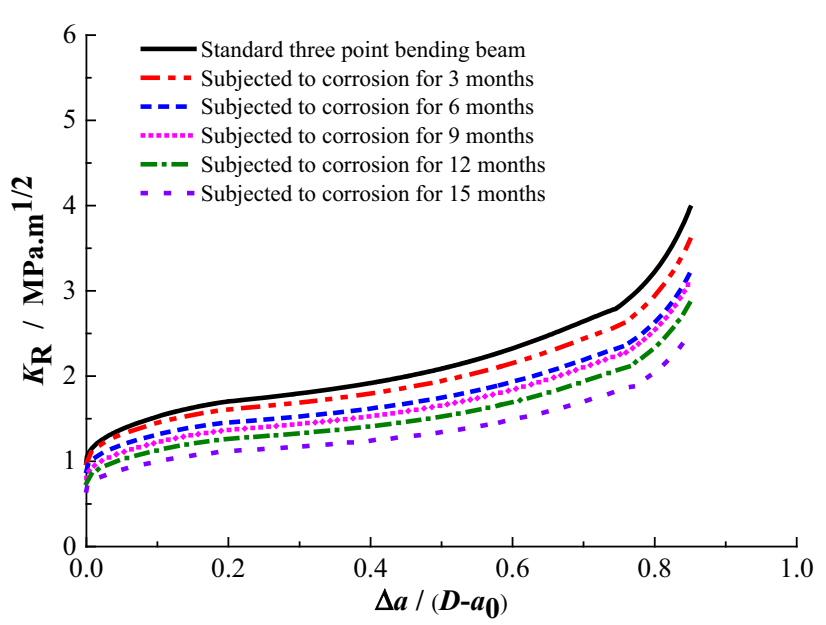

Figure 12. $K_{\mathrm{R}}$-curves (bilinear softening curve).

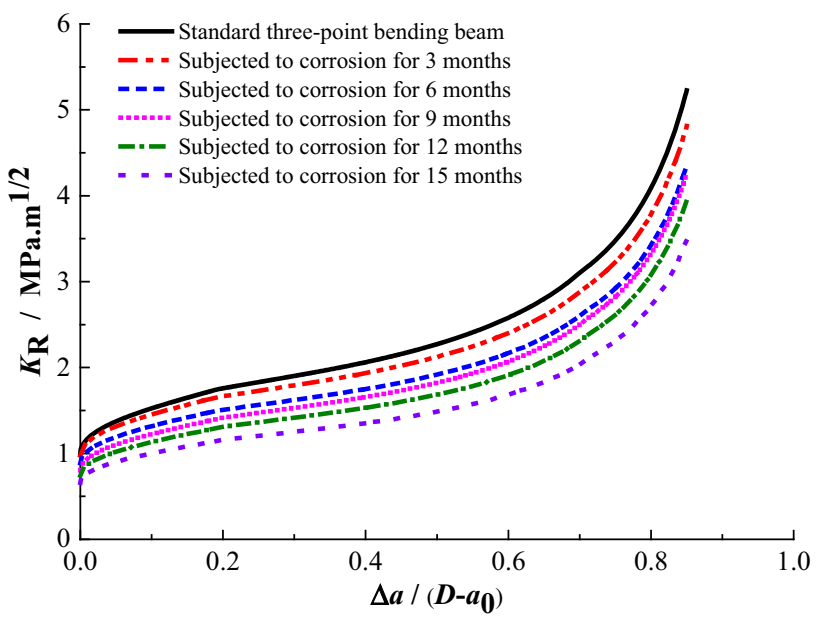

Figure 13. $K_{\mathrm{R}}$-curves (nonlinear softening curve).

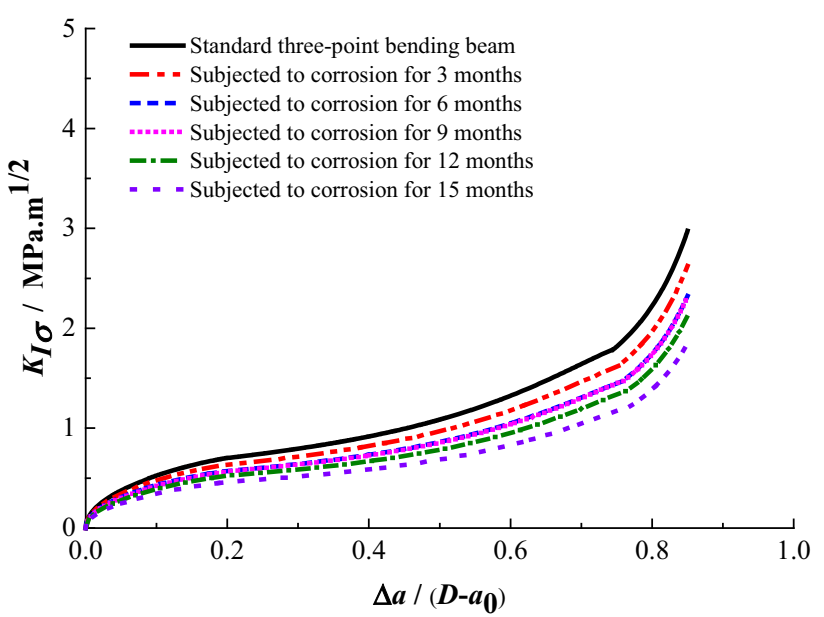

Figure 14. $K_{I \sigma}$-curves (bilinear softening curve).

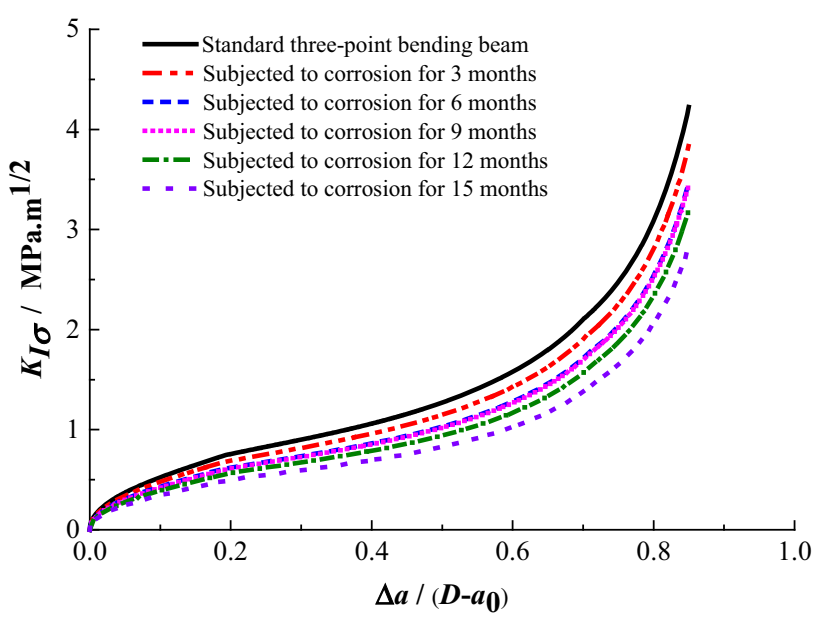

Figure 15. $K_{I \sigma}$-curves (nonlinear softening curve). 


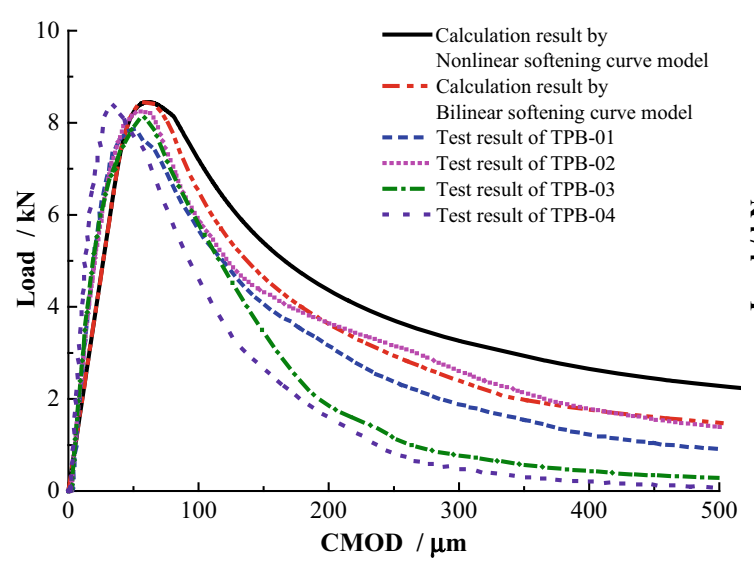

(a) Standard three-point bending beams.

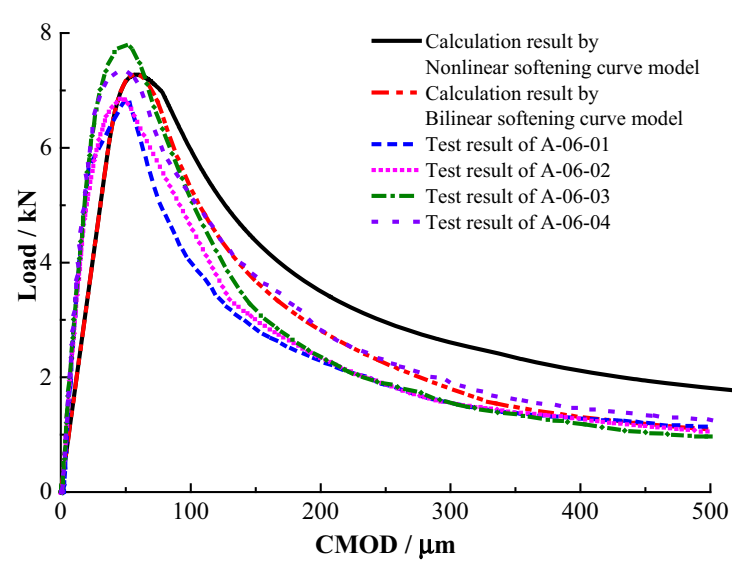

(c) In the 6th month corrosion period.

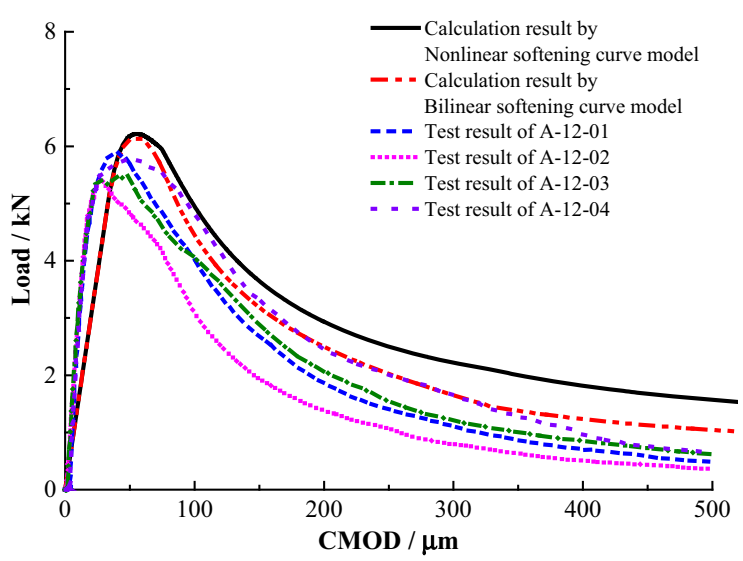

(e) In the 12th month corrosion period

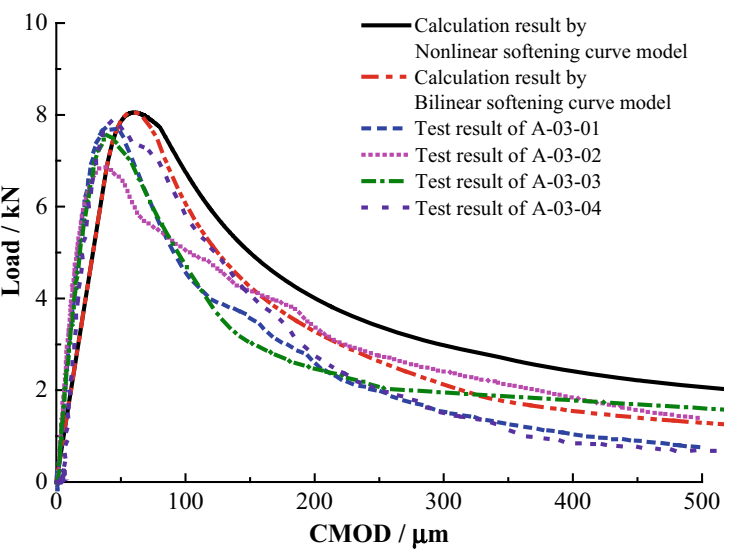

(b) In the 3th month corrosion period.

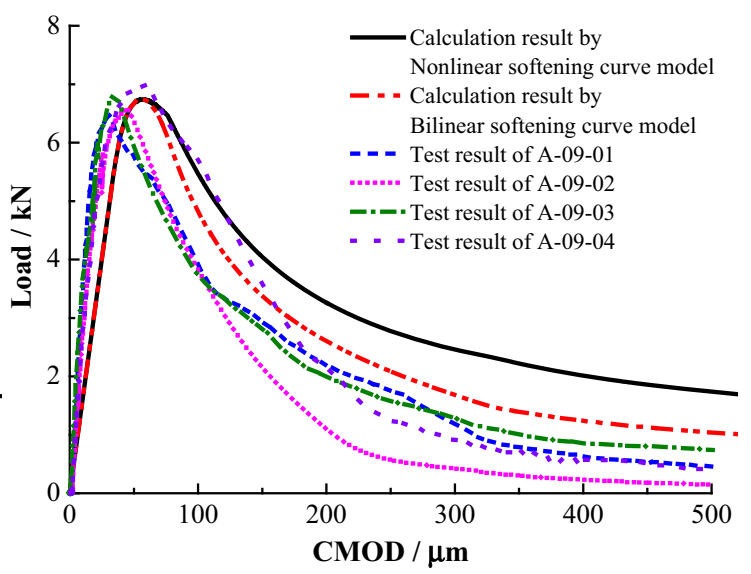

(d) In the 9th month corrosion period.

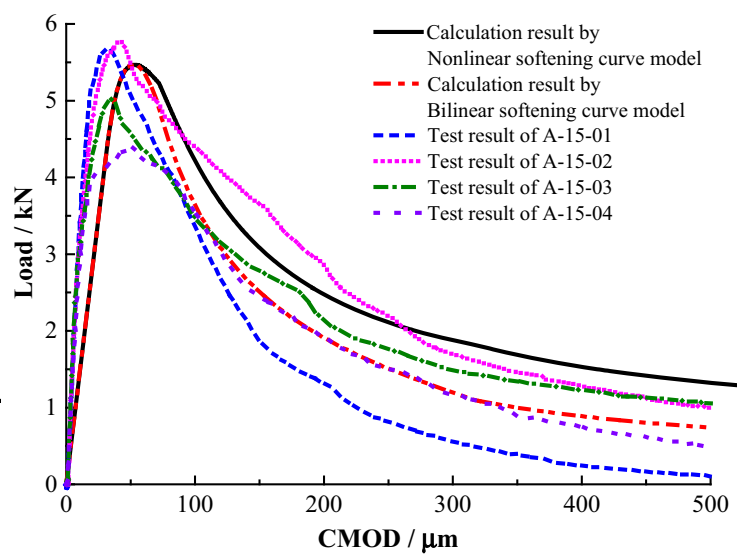

(f) In the 15th month corrosion

Figure 16. Results of $P-\mathrm{CMOD}$ curves in different corrosion periods.

factors generated by cohesive force. The $K_{I \sigma}$-curves of different corrosion degrees are shown in figures 14 and 15 . With the increase of corrosion time, cohesive toughness curves gradually declined, and began to rise slowly. When the structure is soaked in acid condition, hydrogen ions in the solution react with the calcium hydroxide of concrete 
gelled material, reducing the bonding performance of concrete material. Therefore, the concrete material strength gradually reduced, which led to fracture toughness reduction.

It can be seen that the cohesive toughness in the nonlinear softening curve model is significantly higher than that in the bilinear softening curve model when $\Delta a /\left(a-a_{0}\right)>0.2$. This is because closing force of the nonlinear model in the crack propagation period is larger than that of the bilinear model, acting on the fracture propagation zone. Thus, for a particular calculated CMOD, external load of nonlinear model is greater than that of bilinear model, which is used to satisfy the criteria for crack propagation. The descending branch of calculated $P-C M O D$ curve by nonlinear model is higher than that of the bilinear model, which declined slowly. $P$ CMOD curves both in calculation and test are shown in figure 16.

The crack began to move to a stage of unstable crack propagation after the external load reached its maximum. Under the action of load impact, the instability process occurred faster than that indicated by the calculation. Hence, for a particular CMOD value, external load of test was smaller than that of calculation. Afterwards, when the external force reduced to a certain degree, under inertia force effect by load and gravity, external load for crack propagation was less than the calculated value; thus, the descending branch of experimental $P-C M O D$ curves was closer to the $X$-axis. The results of bilinear softening curve are more in conformation with the ones from experiments.

\section{Conclusion}

By considering the variations in corrosion periods, the proposed method can be used to predict the fracture toughness and complete fracture process of concrete subjected to acid corrosion. From the test results and calculation results, the following conclusions are drawn:

(1) For the concrete specimens subjected to acid corrosion, the maximum bearing load and fracture properties deteriorated. Comparing results of standard three-point bending beam test, the average value of maximum load decreased from 8.2540 to $5.2201 \mathrm{kN}$, and the initial cracking load also decreased from 6.5386 to $4.2098 \mathrm{kN}$ after corrosion duration of 15 months. Initial fracture toughness $K_{I \mathrm{c}}^{\mathrm{ini}}$ and unstable fracture toughness $K_{I \mathrm{c}}^{\mathrm{un}}$ incurred a substantial percentage reduction of $34.36 \%$ and $30.99 \%$, respectively.

(2) The initial fracture toughness descended gradually at the beginning of the first 3 months and showed a significant drop at the later period, whereas the unstable fracture toughness $K_{I \mathrm{c}}^{\mathrm{un}}$ was more sensitive to acid attack, representing a similar trend of the linear downward change law with the increase of corrosion duration.
(3) The calculated maximum load $P_{\max }$ was close to the experimental results by means of bilinear softening law, as well as that of the nonlinear. Similarly, the calculation results of unstable fracture toughness $K_{I \mathrm{c}}^{\mathrm{un}}$ lead to a similar conclusion.

(4) Based on the calculated P-CMOD curves obtained by the proposed method, the maximum loads decreased gradually, while $\mathrm{CMOD}_{\mathrm{c}}$ decreased slightly with increasing corrosion duration. Meanwhile, structure fracture energy decreased, making the structure more vulnerable to failure.

(5) The influence of acid corrosion on fracture properties is given by the calculated results of cohesive toughness curves in entire crack propagation. With the increase of corrosion duration, cohesive toughness curves gradually decreased, and later increased slowly. Cohesive toughness in the nonlinear softening curve model was significantly higher than that in the bilinear softening curve model when $\Delta a /\left(a-a_{0}\right)>0.2$, in the crack propagation period. $K_{\mathrm{R}}$-curves in different corrosion periods were obtained by the proposed method.

(6) The rise of calculated $P-C M O D$ curves basically agreed with that of the experiment results, but the descending branch of the experimental results showed some differences with the calculated results. Calculated results by bilinear softening law had more similarities with the experimental results.

\section{Acknowledgements}

This research has been partially supported by the National Funds for Distinguished Young Scientists of China (51325904) and the National Major Scientific Instruments Development Project of China (51527811). The authors thank the reviewers for their useful comments and suggestions that helped in improving the paper.

\section{References}

[1] Wang Y, Niu D T and Song Z P 2017 Effect of acid rain erosion on steel fiber reinforced concrete. J. Wuhan Univ. Technol. 32(1): 121-128

[2] Balafas I and Burgoyne C J 2010 Environmental effects on cover cracking due to corrosion. Cem. Concr. Res. 40(9): $1429-1440$

[3] Xie S D, Qi L and Zhou D 2004 Investigation of the effects of acid rain on the deterioration of cement concrete using accelerated tests established in laboratory. Atmos. Environ. 38(27): 4457-4466

[4] Fan Y F, Hu Z Q, Luan H Y and Chen A 2014 A study of deterioration of reinforced concrete beams under various forms of simulated acid rain attack in the laboratory. Struct. Eng. Mech. 52(1): 35-49 
[5] Yu J T, Yu K Q and Lu Z D 2012 Residual fracture properties of concrete subjected to elevated temperatures. Mater. Struct. 45(8): 1155-1165

[6] Reis J M L 2010 Fracture assessment of polymer concrete in chemical degradation solutions. Constr. Build. Mater. 24(24): 1708-1712

[7] Wang H L, Guo C L and Sun X Y 2012 Effect of calcium dissolution on the fracture properties of concrete exposed to nitric acid environment. Adv. Mater. Res. 374-377: 1974-1978

[8] Xu S L and Zhang X F 2008 Determination of fracture parameters for crack propagation in concrete using an energy approach. Eng. Fract. Mech. 75(15): 4292-4308

[9] Abdalla H M and Karihaloo B L 2004 A method for constructing the bilinear tension softening diagram of concrete corresponding to its true fracture energy. Mag. Concr. Res. 56(10): 597-604

[10] Karihaloo B L, Abdalla H M and Xiao Q Z 2006 Deterministic size effect in the strength of cracked concrete structures. Cem. Concr. Res. 36(1): 171-188

[11] Bažant Z P 2002 Concrete fracture models: testing and practice. Eng. Fract. Mech. 69(2): 165-205

[12] Xu S L and Reinhardt H W 1999 Determination of double-K criterion for crack propagation in quasi-brittle materials, part I: experimental investigation of crack propagation. Int. J. Fract. 98(2): 111-149

[13] Kumar S and Barai S V 2008 Influence of specimen geometry and size-effect on the $K_{R}$-curve based on the cohesive stress in concrete. Int. J. Fract. 152(2): 127-148

[14] Wu Z M, Wu X, Zheng J J, Wu Y F and Dong W 2014 An analytical method for determining the crack extension resistance curve of concrete. Mag. Concr. Res. 66(14): 719-728

[15] Dong W, Wu Z M and Zhou X M 2013 Calculating crack extension resistance of concrete based on a new crack propagation criterion. Constr. Build. Mater. 38(2): 879-889
[16] Yu K Q, Yu J T, Lu Z D and Chen Q Y 2015 Determination of the softening curve and fracture toughness of highstrength concrete exposed to high temperature. Eng. Fract. Mech. 149: 156-169

[17] Zhao Z F, Kwon S H and Shah S P 2008 Effect of specimen size on fracture energy and softening curve of concrete: part I. Experiments and fracture energy. Cem. Concr. Res. 38(8-9): 1049-1060

[18] Yang S T, Hu X Z and Wu Z M 2011 Influence of local fracture energy distribution on maximum fracture load of three-point-bending notched concrete beams. Eng. Fract. Mech. 78(18): 3289-3299

[19] Zhao Y H, Xu S L and Wu Z M 2007 Variation of fracture energy dissipation along evolving fracture process zones in concrete. J. Mater. Civil Eng. 21(1): 47-49

[20] Roesler J, Paulino G H, Park K and Gaedicke C 2007 Concrete fracture prediction using bilinear softening. Cem. Concr. Compos. 29(4): 300-312

[21] Hu S W, Zhang X F and Xu S L 2015 Effects of loading rates on concrete double-K fracture parameters. Eng. Fract. Mech. 149: $58-73$

[22] Kumar S and Barai S V 2012 Effect of loading condition, specimen geometry, size-effect and softening function on double-K fracture parameters of concrete. Sadhana-Acad. Proc. Eng. Sci. 37(1): 3-15

[23] Elices M, Rocco C and Roselló C 2009 Cohesive crack modelling of a simple concrete: experimental and numerical results. Eng. Fract. Mech. 76(10): 1398-1410

[24] Park K, Paulino G H and Roesler J 2008 Determination of the kink point in the bilinear softening model for concrete. Eng. Fract. Mech. 75(13): 3806-3818

[25] CEB-FIP 2010 Model code 2010-first complete draft, vol. 1 